\title{
Manifestasi hidden curriculum dalam pendidikan agama islam
}

\author{
Sabriadi HR ${ }^{a, 1, *}$ \\ ${ }^{a}$ IAIN Bone, Jl. Hos. Cokroaminoto, Kab. Bone, Sulawesi Selatan, Indonesia \\ ${ }^{1}$ sabrielmahadi@gmail.com* \\ * Korespondensi Penulis
}

Article history

Received June 26, 2020

Revised June 26, 2020

Accepted June 27, 2020

Available Online June 30, 2020

Keywords

Manifestation

Hidden curriculum

Islamic education

Manifestasi

Pendidikan agama islam
The discussion in this paper is motivated by the ideality of the objectives of Islamic education which have been formulated formally in the curriculum sometimes are not in accordance with the reality that occurs in the learning process. This is the caused by variousfactors that affect learning outcomes outside the curriculum formulation that has been planned. The accumulation of various factors is called hidden curriculum. It exists as a side product of the of Islamic education that is not planned nor programmed in the formal curriculum. Hidden curriculum of Islamic education is formulated through the the clear and strict regulation or policies that support the achievement of objectives, and are carried out routinely or continuously. It is supported by structuring management of school organizations and harmonization of interactions between school members, as well as policies that support effective learning.

Pembahasan dalam tulisan ini dilatar belakangi oleh idealitas tujuan pendidikan a gama Isla $m$ yang telah dirumuskan da la m kurikulum secara formal terkadang tidak sesuai dengan kenyataan yang terjadi dalam proses pembelajaran. Halini Adanya berbagaifaktor y ang berpenga ruh terhadap hasil pembelajaran di luar rumusan kurikulum yang telah direncanakan. Akumulasi dari berbagai faktor tersebut disebut hidden curriculum. Lahiir sebagai hasil sampingan praktek pendidikan agama Islam yang tidak direncanakan dan tidak deprogram dalam kurikulum secara formal. Hidden curriculum pendidikan agama Islam diformulasi melalui rumusan rules a tau aturan yang.jelas dan tegas, regulations a tau kebijakan yang menunjang tercapainya tujuan, dan dijalankan secara routines atau kontinyu. Ditunjang dengan penataan manajemen organisasi sekolah dan harmonisasi intraksi antar warga sekolah, serta kebijakan yang menopang terlaksananya pembelajaran secara efektif.

This is an open access article under the CC-BY-SA license.

\section{Pendahuluan}

Pelaksanaan pendidikan Agama Islam di berbagai satuan pendidikan sangat tergantung dengan kualitas rumusan kurikulumnya. Rumusan tersebut meliputi kurikulum poten sial atau ku rikulum ideal yang seringkali disebut dengan curriculum dokumen yang di dalamnya telah dijabarkan konstruksi kurikulum sampai pada tahap perumusan tujuan yang diharapkan dalam proses pembelajaran. Kurikulum ini merupakan rencana yang dijadikan sebagai pedoman oleh guru dalam proses pembelajaran. Oleh karena itu, setiap guru seharusnya dapat melaksanakan kegiatan pembelajaran sesuai dengan tuntutan kurikulum yang telah dirumuskan dalam kurikulum ideal. Oleh karena kurikulum ini berfungsi sebagai pedoman, maka sering kali juga disebut dengan kurikulum tertulis (written curriculum). 
Output dari curriculum document tersebut menuntut adanya curriculum implementation yang berfungsi untuk melaksanakan berbagai rumusan yang ada dalam curriculum dokumen. Aksi nyata dari hal tersebut dituangkan dalam bentuk pembelajaran di kelas. Kurikulum ini sering juga disebut dengan kurikulum aktual (actual curriculum) yang secara nyata dapat dilaksanakan oleh guru sesuai dengan kondisi dan keadaan ada. Harapan yang tersurat dalam rumusan tujuan kurikulum idealnya harus berbanding lurus dengan hasil implementasi di lapangan.

Begitu juga dengan pembelajaran Pendidikan Agama Islam yang rumusan tujuannya dianggap sangat ideal, karena menyelaraskan antara pertumbuhan fisik dan mental, jasmani dan rohani, pengembangan individu dan masyarakat, serta kebahagiaan dunia dan akhirat. Konsep tersebut sangat potensial melahirkan peserta didik yang memiliki perkembangan secara paripurna. Namun demikian, kadang kala idealitas tujuan yang diharapkan tidak sesuai dengan kenyataan yang terjadi karena disebabkan beberapa alasan. Pertama, keterbatasan sarana dan prasaran sebagai daya dukung pelaksanaan kurikulum ideal di sekolah. Kedua, ketersediaan sumber daya manusia yang tidak lain adalah kemampuan guru dalam mengimplementasikan kurikulum dalam proses pembelajaran. Ketiga, bisa tidaknya kurikulum ideal dilaksanakan oleh setiap guru, juga tergantung pada dukungan kebijakan sekolah yang bersangkutan.

Fakta yang tidak boleh dinafikkan adalah adanya berbagai faktor y ang berpengaruh terhadap hasil pembelajaran di luar rumusan kurikulum yang telah direncanakan. Akumulasi dari berbagai faktor tersebut dinamakan dengan hidden curriculum atau kurikulum tersembunyi. Istilah ters ebut menunjuk pada segala sesuatu yang dapat berpengaruh terhadap keberlangsungan pembelajaran, yang berpotensial untuk mendorong atau meningkatkan bahkan melemahk an u saha pencapaian tujuan pembelajaran Pendidikan Agama Islam.

Konsep hidden curriculum lahir secara alamiah yang pada saat perumu san kurikulum secara formal tidak diperkirakan akan muncul sebagai aspek yang berpengaruh dan memberikan sumbangsih terhadap hasil pembelajaran. Intinya Hidden curriculum merupakan praktek dan hasil yang tidak direncanakan dalam kurikulum atau program sekolah. Oleh karena, eksistensi hidden curriculum dalam pendidikan agama Islam kadangkala memberikan efek yang positif, bahkan dilain sisi memberikan dampak negatif, maka perlu dikaji secara mendalam tentang konsep hidden curriculum pendidikan agama Islam itu sendiri, dan strategi pengembangannya dalam pendidikan agama Islam di sekolah.

\section{Metode}

\subsubsection{Jenis Penelitian}

Penulisan artikel ini merupakan jenis tulisan yang bersifat literatur review atau studi pustaka. Data dalam artikel ini disajikan secara deskriptif yang menunjukkan suatu kajian ilmiah yang dapat dikembangkan dan diaplikasikan lebih lanjut. Objek penulisan dalam artikel ini tentang manifestasi hidden curriculum dalam pendidikan agama Islam, yang ditinjau dari konsep dan strategi pengembangannya dalam pendidikan agama Islam di Sekolah.

\subsubsection{Teknik Pengumpulan Data}

Teknik yang digunakan dalam pengumpulan data dimulai dengan mengu mpulkan referensi referensi yang relevan, baik dalam bentuk teks-teks tertulis maupun soft copy edition, seperti jurnal ilmiah, ebook, artikel online, dan publikasi pemerintah. Referensi soft copy edition dapat diperoleh dari sumber internet yang diakses secara online. Kedua referensi tersebut merupakan sumber u tama dalam studi pustaka yang menjelaskan variabel-variabel dalam penulisan artikel ini. Setelah dilakukan pencarian referensi yang relevan dengan data yang dibutuhkan, kemudian penulis menganalisis data-data yang ada. Langkah selanjutnya adalah memilah-milah informasi yang relevan dengan persoalan yang dibahas hingga akhirnya terbentuk sebuah solusi dari masalah y ang dibahas dari artikel ini.

\subsubsection{Teknik Analisis Data}

Adapun proses yang dilakukan dalam penulisan artikel ini adalah Mencari, yaitu mencari sumber data dari buku, koran, jurnal, dan artikel online yang sesuai dengan masalah y ang ak an dikaji; Mengidentifikasi, yaitu memilih sumber data dan informasi yang telah dikumpulkan; Mempelajari, yaitu berusaha untuk memahami lebih jauh tentang sumber data dan informasi yang diperoleh sesuai 
dengan masalah yang dibahas; Menganalisis, yaitu membahas sumber data dan informasi dengan melakukan pendekatan yang sesuai dengan masalah yang akan dikaji secara mendalam; dan Mengevaluasi, yaitu melakukan penilaian tentang layak atau tidaknya sumber data dan informasi yang diperoleh untuk dijadikan referensi terhadap masalah yang dikaji serta per lu atau tidaknya melakukan suatu revisi.

\section{Hasil dan Pembahasan}

\subsection{Hidden Curriculum Pendidikan Agama Islam}

Kurikulum merupakan suatu komponen yang sangat berpengaruh dalam menyukseskan pelaksanaan sistem pendidikan. Sebagai salah satu alat untuk mencapai tujuan pendidikan, maka kurikulum memiliki peran yang sangat urgen sebagai pedoman pelak sanaan pembelajaran pada semua tingkat dan jenjang pendidikan.

Pada dasarnya kurikulum adalah suatu rencana atau program y ang dih arapkan selama studi berlangsung. Kurikulum merupakan rencana pelaksanaan pendidikan baik dalam lingkup kelas, sekolah, daerah, wilayah maupun nasional (Sabriadi, 2011). Hal tersebut dijabarkan dalam perumusan tujuan yang akan dicapai, materi yang akan dipelajari, dan metode yang digunakan serta evaluasi yang digunakan dalam proses pembelajaran. Kurikulum mencakup pengertian y ang lu as meliputi kurikulum potensial, kurikulum aktual, dan kurikulum tersembunyi ( hidden curriculum) (Sukiman, 2015).

Kurikulum potensial adalah suatu rencana atau program tertulis yang menjadi pedoman bagi guru dalam melaksanakan kegiatan pembelajaran di sekolah, sedangkan kurikulum aktual adalah kurikulum yang dapat dilaksanakan secara rill sesuai dengan kondisi dan keadaan y ang ada. Oleh sebab rumusan kurikulum potensial terkadang tidak bisa diimplementasikan dengan sempurna oleh guru karena tuntutan tidak sesuai dengan keadaan dan kon disi sekolah. Proses pengembangan kurikulum memang memberikan ruang terhadap guru agar lebih berekspresi dan mengadaptasi rumusan kurikulum untuk disesuaikan dengan kondisi sekolah. Hal ini dilandasi dengan prin sip pengembangan kurikulum yang disebut dengan prinsip fleksibelitas (Hamdi, 2017). Untuk melihat keterkaitan antara kurikulum potensial, kurikulum aktual, dan hidden curriculum dapat dilihat Gambar 1 (Ibrahim, 2012).

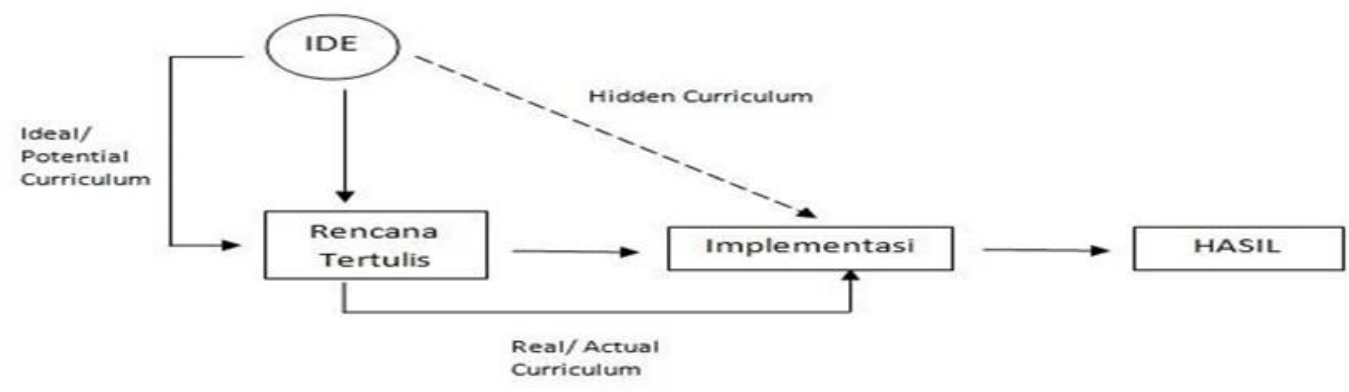

Gambar. 1. Keterkaitan Kurikulum Potensial, Kurikulum Aktual, dan Hidden Curriculum

Adapun hidden curriculum pertama kali diperkenalkan oleh Philip W. Jackson dalam buk un ya Life in Classrooms yang secara kritis mencari jawaban kekuatan utama apa yang terdapat dalam sekolah sehingga bisa membentuk habitus budaya seperti kepercayaan, sikap dan pandangan murid. Konsep hidden curriculum menurut Jackson dapat mempersiapkan murid dalam kehidupan y ang dianggap membosankan dalam masyarakat industri. Dalam buku itu, Jakcson ju ga menjelaskan bagaimana murid-murid merasakan tentang dunia sekolah, bagaiman a guru merasakan perilaku muridnya. Tetapi Jackson tidak setuju dengan berbagai dikotomi tersebut. Ia berpendapat dikoto mi tersebut harus dihapuskan (Hidayat, 2011).

Hidden curriculum merupakan aturan-aturan sosial dan perilaku yang diharapkan berdas arkan segala sesuatu yang tidak tertulis. Konsep ini juga menjadi kelebihan Jackson dalam berbagai karya-karyanya yang menunjukkan praktik hidden curriculum dalam kelas selama periode 1950 - 
1960. Ia mengemukakan argumen pentingnya pemahaman pendidikan sebagai proses sosialis asi (Hidayat, 2011).

Sebelum Jackson memperkenalkan istilah hidden curriculum, Emile Durkhaim juga menganalisis fenomena ini. Meski tidak menyebut hidden curriculum, tapi penjelasan Durk haim memberikan akar historis lahirnya konsep hidden curriculum tersebut. Singkatn ya, Durkhaim menemukan sebuah realitas bahwa banyak materi yang disampaikan guru, tetapi tidak tertulis dan tidak dituangkan dalam panduan mengajar di kelas. Penjelasan Durkhaim ini memberikan kontribusi tentang analisis hidden curriculum (Hidayat, 2011).

Secara akademik hidden curriculum menjadi salah satu kajian yang menarik terlihat dari berbagai eksplorasi oleh sejumlah pendidik. Dimulai dari dengan buku Pedagogy of the Opporessed yang dipublikasikan tahun 1972 oleh Paulo Freire. Paulo Freire mengeksplorasi berbagai dampak dari pengajaran terhadap siswa, sekolah, dan masyarakat secara menyelu ruh (Hidayat, 2011).

Hidden curriculum, secara etimologi berasal dari bahasa inggris yang terdiri dari dua kata yaitu, hidden dan curriculum. Hidden artinya tersembunyi dan curriculum artinya kurikulum. Kurikulum pada hakikatnya berisi ide atau gagasan yang dituangkan dalam bentuk dokumen atau tulisan secara sistematis dan logis yang memperhatikan unsur scope dan squence, selanjutnya dokumen tertulis inilah yang dinamakan kurikulum yang terencana (currriculum document or writen curriculum) (Sanjaya, 2008). Salah satu isi dari dokumen kurikulum adalah sejumlah tujuan yang harus dicapai oleh peserta didik. Tujuan itulah yang dijadikan ped oman oleh guru dalam proses pembelajaran. Selain sesuai dengan prilaku yang diharapkan dalam rumusan tujuan tersebut, terkadang ada prilaku hasil belajar yang muncul di luar tujuan yang telah dirumuskan, inilah hakikat dari hidden curriculum, yakni efek yang muncul sebagai hasil yang sama sekali di luar tujuan y ang telah dideskripsikan.

Hidden curriculum tidak terlihat dipermukaan, tetapi bukan berarti eksistensinya hilang dalam pembelajaran, jadi kurikulum ini tidak direncanakan, tidak diprogram dan tidak dirancang sebagaimana kurikulum potensial atau kurikulum ideal, tetapi memberikan pengaruh baik secara langsung maupun tidak langsung terhadap output proses pembelajaran. Proses pembelajaran sebagai hasil interaksi antara guru, peserta didik dan materi pelajaran, seringkali tidak disadari "diperhatikan, dipelajari bahkan ditiru" siswa, sekalipun hal tersebut tidak direncanakan, dan karena itu seringkali terabaikan sehingga luput dari perhatian guru. Inilah yang disebut hidden curriculum. Artinya hidden curriculum muncul sebagai hasil sampingan (side effects) dari interaksi antar guru, peserta didik dan materi serta lingkungan belajar.

Adapun pendidikan agama Islam menurut Nazaruddin adalah us aha sadar dan terencana untuk menyiapkan peserta didik dalam meyakini, memahami, menghayati, dan mengamalkan ajaran agama Islam melalui kegiatan bimbingan, pengajaran dan latihan (Rukajat, 2018). Pengertian tersebut menunjukkan bahwa pendidikan agama Islam merupakan kegiatan yang dilakukan seseorang untuk menanamkan nilai-nilai ajaran Islam yang diwuju dkan dalam sikap kehidu pan sehari-hari.

Menurut hemat penulis bahwa hidden curriculum pendidikan agama Islam merupakan manifestasi praktek pendidikan agama Islam yang tidak direncanakan dan tidak deprogram dalam kurikulum. Wujud dari proses interaksi antara stakeholder sekolah baik guru, peserta didik, maupun warga sekolah yang lain sehingga berpengaruh terhadap perubahan tingkah laku peserta didik y ang dapat berkontribusi terhadap ketercapaian tujuan pendidikan agama Islam.

Praktek hidden curriculum sebenarnya terdapat dalam al-Quran Surah al-Kahfi ayat 66-

67.

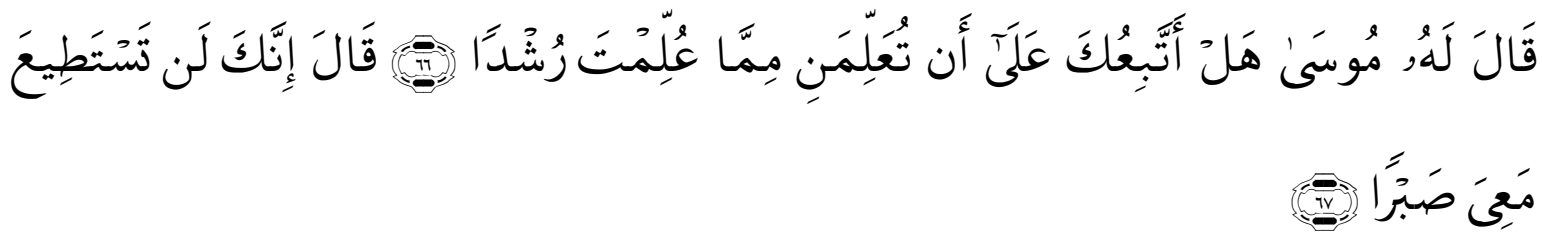


Musa Berkata kepada Khidhr: "Bolehkah Aku mengikutimu supaya kamu

mengajarkan kepadaku ilmu yang benar di antara ilmu-ilmu yang Telah diajarkan kepadamu?". Dia menjawab: "Sesungguhnya kamu sekali-kali tidak akan sanggup sabar bersama Aku (Agama, 2017).

Q.S al-Kahfi ayat 66-67 sesungguhnya merupakan implementasi hidden curriculum yang terja di antara nabi Musa dengan nabi Khidir sekalipun pada masa itu belum ada teori tentang hidden curriculum. Kecerdasan nabi khidir memberikan buah pelajaran tersembu nyi le wat prilaku yang dilakukannya selama nabi Musa berada bersamanya. Selama nabi Musa menemani perjalanan nabi Khidir, beliau selalu bertanya tentang perbuatan yang dilakukan oleh nabi Khidir yang dianggapnya tidak masuk akal. Jawaban yang dilontarkan oleh nabi khidir pun selalu mengandung makna yang tersembunyi, seolah-olah menguji kesabaran nabi Musa yang diawal kebersamaannya sudah diperingatkan oleh nabi Khidir bahwa beliau tidak akan sanggup bersabar hingga akhir perjalanan. Namun pada akhir perjalanan nabi Khidir menjelaskan maksud setiap perbuatan yang beliau lakukan dan nabi Musa dapat mengambil pelajaran dari setiap kejadian yang memiliki makna tersembunyi di dalamnya tersebut. Hal ini termaktub dalam Q.S. al-Kahfi ayat 78-82 sebagai berikut:

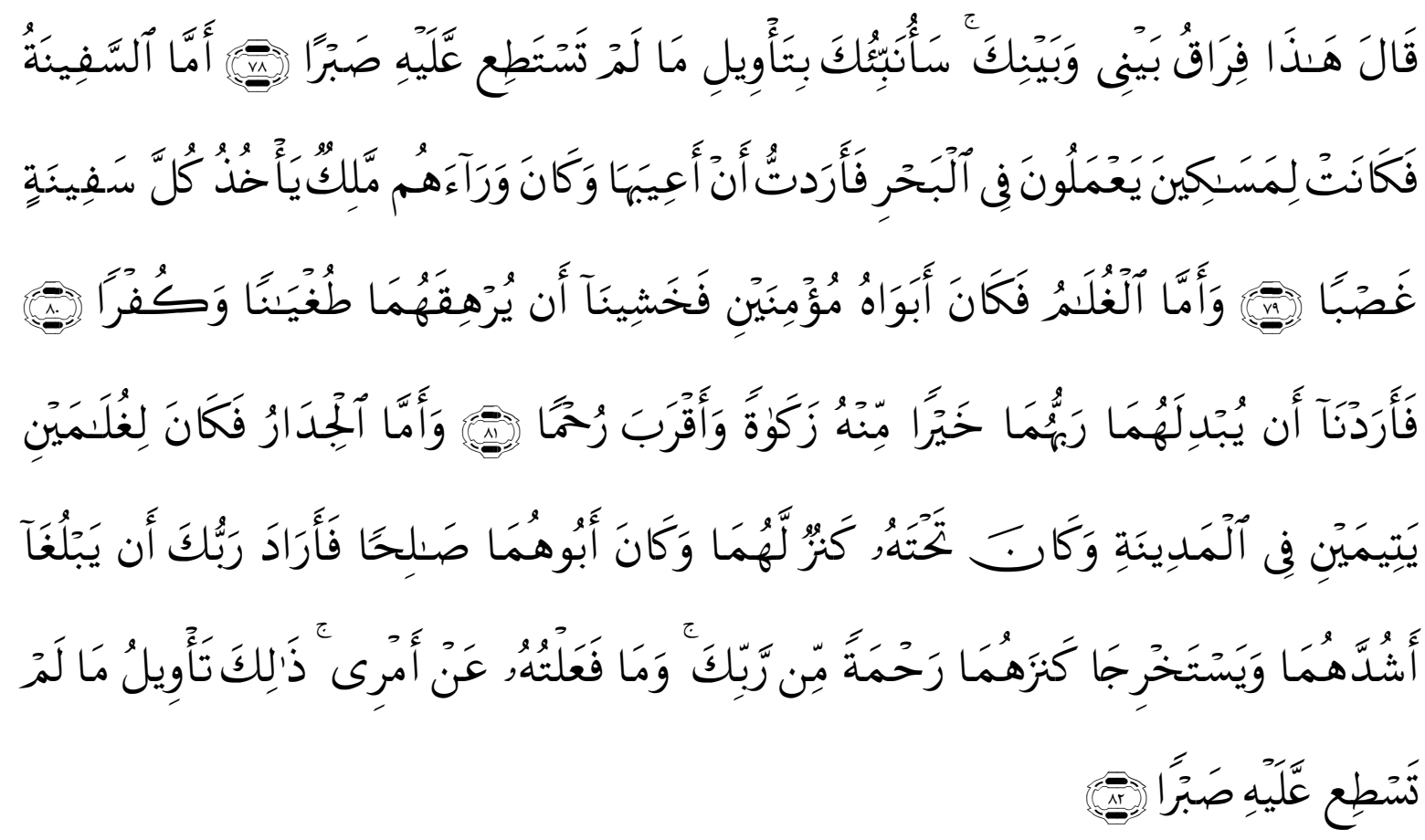

Khidir berkata: "Inilah perpisahan antara Aku dengan kamu; kelakakan kuberitahukan kepadamu tujuan perbuatan-perbuatan yang kamu tidak dapat sabar terhadapnya. Adapun bahtera itu adalah kepunyaan orang-orang miskin yang bekerja di laut, dan Aku bertujuan merusakkan bahtera itu, Karena di hadapan mereka ada seorang raja yang merampas tiap-tiap bahtera. Dan adapun anak muda itu, maka keduanya adalah orang-orang mukmin, dan kami khawatir bahwa dia akan mendorong kedua orang tuanya itu kepada kesesatan dan kekafiran. Dan kami menghendaki, supaya Tuhan mereka mengganti bagi mereka dengan anak lain yang lebih baik kesuciannya dari anaknya itu dan lebih dalam kasih sayangnya (kepada ibu bapaknya). Adapun dinding rumah 
adalah kepunyaan dua orang anak yatim di kota itu, dan di bawahnya ada harta benda simpanan bagi mereka berdua, sedang ayahnya adalah seorang yang saleh, maka Tuhanmu menghendaki agar supaya mereka sampai kepada kedewasaannya dan mengeluarkan simpanannya itu, sebagai rahmat dari Tuhanmu; dan bukanlah Aku melakukannya itu menurut kemauanku sendiri. demikian itu adalah tujuan perbuatan-perbuatan yang kamu tidak dapat sabar terhadapnya" (Agama, 2017).

Ayat tersebut menggambarkan praktek hidden curriculum dibalik perilaku nabi Khidir selama dalam perjalanan yang secara kasat mata tidak dipahami oleh nabi Musa, tetapi mengandung makna yang tersembunyi. Hal tersebut beliau lakukan berdasarkan perintah dari Allah Swt kepadanya sehingga Nabi Musa dapat mengambil pelajaran.

Peristiwa nabi Khidir bersama nabi Musa sama halnya seperti guru kepada peserta didik yang memiliki hidden curriculum. Hidden curriculum dalam Pendidikan Agama Islam bias terwuju d salah satunya dalam bentuk perilaku orang-orang disekitar peserta didik yang bertujuan mempengaruhi tingkah lakunya, sehingga peserta didik mampu menyesuaikan diri sebaik mun gkin dengan lingkungannya. Adanya perubahan tingkah laku yang terjadi di dalam diri peserta didik memungkinkannya untuk berfungsi secara sempurna dalam menjalani kehidupan di masyarakat.

Hidden curriculum pendidikan agama Islam juga dapat terjadi melalui proses interaksi guru, peserta didik, struktur kelas, dan keseluruhan pola organisasi dan lain sebagain ya dalam suatu hubungan sekolah yang pada awalnya tidak tercantum dalam kurikulum secara formal, tetapi berfungsi untuk membantu mewujudkan tujuan pendidikan agama Islam.

Ada tiga unsur penting yang harus ada dalam hidden curriculum pendidikan agama Islam, yaitu: dinamika kelas, interaksi antar guru dan peserta didik, dan relasi kuasa. Hiden curriculum mengedepankan pembelajaran sikap, norma, kepercayaan, dan nilai y ang diekspresik an sebagai ritual dan aturan (Mustaghfiroh \& Mustaqim, 2014). Memaksimalkan tiga unsur tersebut potensial untuk mencapai fungsi hiden curriculum terhadap pendidikan agama Islam, yaitu:

1) Hidden curriculum berfungsi sebagai alat dan metode untuk menambah khazanah pengetahuan tentang pendidikan agama Islam peserta didik diluar materi yang tidak termasuk dalam silabus;

2) Hidden curriculum merupakan salah satu daya dukung tercapainya tujuan pendidikan agama Islam yang tidak diprogramkan dalam kurikulum secara formal;

3) Hidden curriculum berfungsi mengembangkan kecakapan dan keterampilan pendidikan agama Islam sebagai bekal untuk mengarungi kehidupan di masa yang akan datang;

4) Hidden curriculum merupakan mekanisme kontrol sosial terhadap perilaku peserta didik maupun guru. Seluruh perilaku guru akan menjadi panutan dan teladan yang akan ditransmisikan kepada peserta didik;

5) Hidden curriculum berfungsi untuk menjadi motivasi dalam meningkatkan prestasi belajar peserta didik. Terdapat berbagai kegiatan yang tidak terncana dalam kurikulum secara formal tetapi membantu proses pengembangan kompetensi peserta didik (Hidayat, 2011). Kegiatan shalat berjamaah mislanya, dapat mendukung tercapainya tujuan pembelajaran materi Fiqih, atau kegaiatan tadarrus al-Quran yang mendukung ketercapaian tujuan pembelajaran al-Quran Hadis. Contoh kegiatan merupakan pengejewantahan terhadap pengembangan presta peserta didik.

Upaya untuk memaksimalkan fungsi hidden curriculum dalam pendidikan agama Islam perlu dibentuk budaya dan iklim sekolah yang positif. Iklim sekolah y ang k on dusif berdampak besar terhadap perkembangan pendidikan peserta didik, terutama yang berkaitan dengan aspek ranah afektif, yang menyangkut dengan emosi serta sikap siswa (Caswita, 2019). Perilaku peserta didik sedikit banyaknya dipengaruhi oleh lingkungan dimana ia berada, termasuk didalamnya iklim sekolah. Iklim sekolah yang merupakan bagian dari hidden curriculum berkonstribusi besar terhadap perkembangan peserta didik. Sekolah merupakan tempat anak belajar berinteraksi, sehingga segala pengalaman peserta didik di sekolah menjadi bekal mendasar bagi proses perkembangan selanjutnya. 


\subsection{Strategi Pengembangan Hiddeen Curriculum Pendidikan Agama Islam di Sekolah}

Objek utama dalam pengembangan kurikulum pendidikan agama Islam adalah peserta didik itu sendiri. Perkembangan peserta didik berbanding lurus dengan hasil pengalaman belajar yang diperoleh melalui pelajaran yang disajikan di sekolah, baik melalui ku rikulum tertulis, mau pun yang tidak tertulis (hidden curriculum) (Mustaghfiroh \& Mustaqim, 2014).

Dalam upaya untuk memaksimalkan pelaksanaan pendidikan agama Islam di sekolah, perlu diciptakan iklim sekolah yang kondusif agar pendidikan agama Islam tid ak hany a dipahami oleh peserta didik secara ritual, tetapi nilai-nilai ritual dalam Islam mampu diinternalisasikan dalam kehidupannya. Salah satu aspek yang bisa menopang adalah menyadari eksistensi hidden curriculum dalam praktek pendidikan agama Islam dan memaksimalkan keberadaan nya sebagai wadah untuk menunjang ketercapaian tujuan pendidikan agama Islam. Ada tiga hal y ang perlu dikembangkan agar hidden curriculum dapat terbentuk dalam praktek pendidikan agama Islam, yaitu:

1) Rules atau aturan, sekolah harus memiliki aturan yang jelas dan tegas agartercipta situasi dan kondisi yang kondusif untuk belajar. Dengan demikian, peserta didik merasa nyaman dalambelajar dan mampu mengekspresikan kegiatan belajarnya dalam suasana yang tetap terkontrol oleh sekolah.

2) Regulations atau kebijakan, sekolah harus berani menetapkan kebijakan yang mampu menopang ketercapaian tujuan pendidikan agama Islam, kebijakan tersebut tidak hanya terkait terhadap siswa, tetapi untuk sетиа komponen sekolah dirumuskan dalam formulasi yang berbeda.

3) Routines atau kontinyu, sekolah harus mengimplementasikan segala aturan dan kebijakan dengan kontinyu, dilaksanakan secara tegas tetapi tetap berada dalam koridor adaptif dengan suasana dan kondisi, tujuanya agar kebijakan tersebut dapat diterima dengan baik dan terus dilaksanakan (Caswita, 2019).

Di samping itu, dalam upaya menanamkan hidden curriculum dalam pendidikan agama Islam terdapat dua elemen yang perlu dikaji, yakni elemen struktural (organisasi), dan elemen budaya. Dua elemen ini yang menjadi rujukan untuk mengembangkan hidden curriculum pendidikan agama Islam di sekolah. Elemen struktural menjelaskan tentang pembelajaran di kelas, berbagai kegiatan sekolah diluar kegiatan belajar, dan berbagai fasilitas di sekolah, sedangkan elemen kultural mencangkup norma sekolah, etos kerja, peran dan tanggungjawab, relasi sosial, ritu al dan perayaan ibadah, toleransi, kerjasama, kompetisi, ekspektasi gu ru terhadap sis wa, dan disiplin waktu (Hidayat, 2011).

Bentuk-bentuk hidden curriculum termasuk dalam pendidikan agama Islam ju ga mencangkup praktik, prosedur, peraturan, hubungan sosial dan strukturkelas, latihan otoritas guru, aturan y ang mengatur guru dan siswa, aktivitas belajar, penggunaan bahasa, buku teks, ukuran disiplin, berbagai arsitektur, dan prioritas hukuman (Hidayat, 2011).

Kurikulum pendidikan agama Islam yang telah dirumuskan dan direncanakan perlu mengintegrasikan dan mengakomodir keberadaan hidden curriculum yang potensial muncul pada saat pelaksanaan pembelajaran di sekolah, sekalipun tidak diperkirakan pada saat proses perencanaan.

Ada dua aspek yang dapat mempengaruhi hidden curriculum dalam proses pendidikan termasuk dalam pelasanaan pendidikan agama Islam, yaitu aspek relatif tetap dan aspek yang dapat berubah. Aspek relatif tetap adalah ideologi, keyakinan, nilai budaya masyarakat y ang mempengaruhi sekolah termasuk menentukan jenis budaya yang patut dan tidak patut diwariskan kepada peserta didik. Sedangkan aspek yang dapat berubah meliputi variabel organisasi, sistem sosial dan kebudayaan. Allan A Glatthom dalam bukunya Dede Rosyada juga menjelaskan bahwa ketiga variabel tersebut penting dalam pengelolaan dan pengembangan sekolah. Variabel organisasi y akni kebijakan guru dalam proses pembelajaran yang meliputi teknik pengelolaan kelas yang dilakukan oleh guru, metode transfer pelajaran, dan sistem kenaikan kelas yang dilakukan oleh guru. Sistem sosial adalah kondisi dan suasana sekolah yang terlihat dari pola-pola hubungan semu a sistem sekolah, yaitu meliputi interaksi sosial antara guru dengan guru, guru dengan peserta didik, guru dengan staf sekolah, dan lain sebagainya. Variabel kebudayaan yakni dimensi so sial y ang ada kaitannya dengan sistem kepercayaan, nilai-nilai, dan sruktur kognitif (Rosyada, 2016).

Eksistensi Hidden Curriculum pendidikan agama Islam perlu dibangun secara kon tinyu dan diformulasi dengan baik agar tidak berseberangan dengan kurikulum formal sekalipun 
keberadaannya tidak direncanakan pada saat perumusan kurikulum. Sifat pengemb angan Hidden Curriculum dalam pendidikan agama Islam memiliki tiga kategori, yaitu:

1) Organisasional, yaitu pengaturan waktu, penyediaan fasilitas dan bahan pembelajaran.

2) Interpersonal, menciptakan wujud hubungan yang harmonis antara guru dengan peserta didik, tenaga kependidikan, orang tua dan sesama peserta didik.

3) Institusional, yaitu segala halyang berhubungan dengan kebijakan, struktursosial dan kegiatan ekstrakurikuler (Faridah, 2015).

Dengan demikian, strategi pengembangan hidden curriculum dalam pendidikan agama Islam harus diawali dengan tata kelola organisasi sekolah yang memadai dan menciptakan hubungan intraksi antar stakeholder sekolah dengan harmonis, serta kemampuan institusi dalam melahirkan kebijakan yang menopang terlaksananya pembelajaran dengan efektif.

\section{Simpulan dan Saran}

Hidden curriculum pendidikan agama Islam adalah hasil sampingan praktek pendidikan agama Islam yang tidak direncanakan dan tidak deprogram dalam kurikulum secara formal. Lahir dari proses interaksi antara warga sekolah yang memberikan dampak positif terhadap perubahan tingkah laku peserta didik yang dapat berkontribusi terhadap ketercapaian tujuan pendidikan agama Islam. Hiden curriculum berfungsi sebagai alat untuk menambah khazanah pengetahuan pendidikan agama Islam peserta didik; Menjadi daya dukung tercapainya tujuan pendidikan agama Islam; Mengembangkan kecakapan dan keterampilan peserta didik; Menjadi mekanis me kontrol so sial terhadap perilaku peserta didik maupun guru; Memberikan motivasi dalam meningkatkan pre stasi belajar peserta didik. Strategi pengembangan hidden curriculum pendidikan agama Islam diformulasi melalui rumusan rules atau aturan yang jelas dan tegas, regulations atau kebijakan yang menunjang tercapainya tujuan pendidikan agama Islam, dan dijalankan secara routines atau kontinyu. Pengembangan hidden curriculum pendidikan agama Islam diawali den gan penataan manajemen organisasi sekolah dan membangun interaksi antar warga sek olah dengan harmonis, serta melahirkan kebijakan yang menopang terlaksananya pembelajaran secara efektif. Hasil pembahasan dalam tulisan ini bersifat teoritis, karena itu untuk memperoleh data yang lebih otentik dan konprehensif tentang hidden curriculum pendidikan agama Islam perlu diad akan pen elitian lapangan lebih lanjut.

\section{Daftar Pustaka}

Agama, D. (2017). Al-Quran dan Terjemahnya. Danakarya.

Caswita, C. (2019). Kurikulum tersembunyi dalam pembelajaran pendidikan agama islam. EDUKASI: Jurnal Penelitian Pendidikan Agama Dan Keagamaan, 17(3).

Faridah, A. (2015). Membangun karakter melalui the hidden curriculum. Al-Mabsut: Jurnal Studi Islam Dan Sosial, 9(2), 107-115.

Hamdi, M. M. (2017). Konsep Pengembangan Kurikulum. Intizam, Jurnal Manajemen Pendidikan Islam, 1(1), 1-13.

Hidayat, R. (2011). Pengantar sosiologi kurikulum. Jakarta: RajaGrafindo Persada.

Ibrahim, R. (2012). Kurikulum dan pembelajaran. Jakarta: Rajagrafindo Persada.

Mustaghfiroh, H., \& Mustaqim, M. (2014). Hidden curriculum dalam pembelajaran PAI. Edukasia: Jurnal Penelitian Pendidikan Islam, 9(1).

Rosyada, D. (2016). Paradigma pendidikan demokratis. Kencana Penada Media Group.

Rukajat, A. (2018). Manajemen pembelajaran. Deepublish.

Sabriadi, A. R. (2011). Pengembangan kurikulum muatan lokal baca tulis Al-Qurán (BTQ): Studi kasus pada MTs al-Junaidiyah Watampone [PhD Thesis]. Universitas Pendidikan Indonesia.

Sanjaya, W. (2008). Kurikulum Dan Pembelajaran (Teori \& Praktek KTSP). Kencana.

Sukiman, S. (2015). Pengembangan kurikulum perguruan tinggi. PT Remaja Rosdakarya. 